\title{
Biopsable neural tissues: toward new biomarkers for Parkinson's disease?
}

\section{Thibaud Lebouvier ${ }^{1,2,3}$, Maddalena Tasselli', Sébastien Paillusson ${ }^{1,2}$, Hélène Pouclet ${ }^{1,3}$, Michel Neunlist ${ }^{1,2}$ and Pascal Derkinderen ${ }^{1,2,3 *}$}

1 Inserm, U913, Nantes, France

2 University Nantes, Nantes, France

${ }^{3}$ Department of Neurology, CHU Nantes, France

\section{Edited by:}

Ritchie Williamson, University of

Dundee, UK

\section{Reviewed by:}

Wendy Noble, King's College London, UK

Ritchie Williamson, University of Dundee, UK

Patrick A. Lewis, University College

London, UK

*Correspondence:

Pascal Derkinderen, Inserm, U913, 1, Place Alexis Ricordeau, 44093 Nantes

Cedex 1, France.

e-mail:derkinderenp@yahoo.fr, pascal. derkinderen@chu-nantes.fr
Biomarkers for Parkinson's disease (PD) are mainly intended for the early diagnosis of the disease and to monitor its progression, two aspects insufficiently covered by clinical evaluation. In the last 20 years, the search for biomarkers has been supported by technological advances in the fields of molecular genetics and neuroimaging. Nevertheless, no fully validated biomarker is yet available, and there is still a need for biomarkers that will complement those already available. Development of biomarkers for PD has been hampered by the fact that the core pathology lies in the brainstem, hidden from direct study in living patients. In this context, the recent observations that clearly demonstrated the presence of PD pathology in peripheral neural tissues provide new opportunities to develop original histopathological markers of the disease. Some of these peripheral tissues, especially the enteric nervous system, by being assessable using routine biopsies, could represent a window to assess in vivo the neuropathological processes occurring in PD.

Keywords: Parkinson's disease, biomarker, alpha-synuclein, autonomic nervous system, enteric nervous system, skin, salivary glands, colonic biopsies
Development of biomarkers for PD has been hampered by the fact that the core pathology lies in the brainstem, hidden from direct study in living patients. However the traditional assumption of PD as a primary disorder of the dopaminergic neurons of the substantia nigra has been reconsidered in the recent years. Recent studies have indeed implicated that the presence of Lewy pathology is much more extensive and affects not only the central nervous system but also peripheral autonomic neuronal circuits. This provides new opportunities for the development of original biomarkers that will directly assess the pathological process in peripheral tissues accessible by biopsy.

\section{IN SEARCH OF BIOMARKERS FOR PD}

Parkinson's disease (PD) is a progressive neurodegenerative condition characterized and diagnosed by the presence of motor and non-motor symptoms (Lees et al., 2009). From a pathological point of view, the two hallmarks of $\mathrm{PD}$ are a loss of dopaminergic neurons in the substantia nigra and the presence in the surviving neurons of inclusions termed Lewy bodies (LB) and Lewy neurites (LN), whose main component is phosphorylated alpha-synuclein (Fujiwara et al., 2002; Anderson et al., 2006).

Parkinson's disease follows a slowly chronic progressive course, and the motor cardinal symptoms of the disease appear only when the degenerative process has progressed for a long time, in most cases probably for more than 10 years (Hawkes et al., 2009). This long premotor phase is nevertheless not clinically silent since nonmotor symptoms such as hyposmia (Ponsen et al., 2004), REMsleep behavior disorder (Postuma et al., 2009), and constipation (Abbott et al., 2001; Savica et al., 2009) can antedate the occurrence of tremor and/or akinesia. In contrast, other non-motor symptoms, especially dementia, are known to occur lately in the evolution of the disease and to reflect disease progression and severity (Chaudhuri et al., 2006).

Currently, diagnosis and progression of PD is based mainly on clinical criteria. Diagnosis of PD relies on the presence of two out of three of major motor signs, namely tremor, bradykinesia, and hypertonia, implying that the diagnosis is made only many years after the real onset of the neurodegenerative process (Hughes et al., 2002). PD can be difficult to diagnose in its early stages, and may be mimicked by other diseases, such as essential tremor, multiple system atrophy and progressive supranuclear palsy (Hughes et al., 2002). Treatment strategies for PD are mostly aimed at relieving motor symptoms and not at modifying the disease process (Thobois et al., 2005). Therefore, a key goal in PD research is the development of drugs capable of preventing or at least slowing the disease progression. Compounding this problem is the difficulty to readily assess $\mathrm{PD}$ progression and/or severity. To date, most of the neuroprotective trials in PD used changes in the clinical UPDRS scale as a primary endpoint (Schapira and Olanow, 2004; Olanow et al., 2009). Such an approach is confounding since many of the drugs proposed to slow progression also improve dopaminergic neurotransmission and treat PD symptoms (Ahlskog, 2007). Consequently, there is a critical need to develop biomarkers that correlate either with the presence or the severity of the disease, for a more precise and early diagnosis of the disease as well as for the assessment of new therapeutic strategies (Figure 1). Technological advances in the field of molecular genetics and in in vivo imaging have allowed the development of some reliable biomarkers either for early diagnosis or to assess disease progression. For instance, transcranial ultrasound (Berg and Becker, 2002), high-field MRI 


\section{Biomarkers in Parkinson's Disease: What For?}

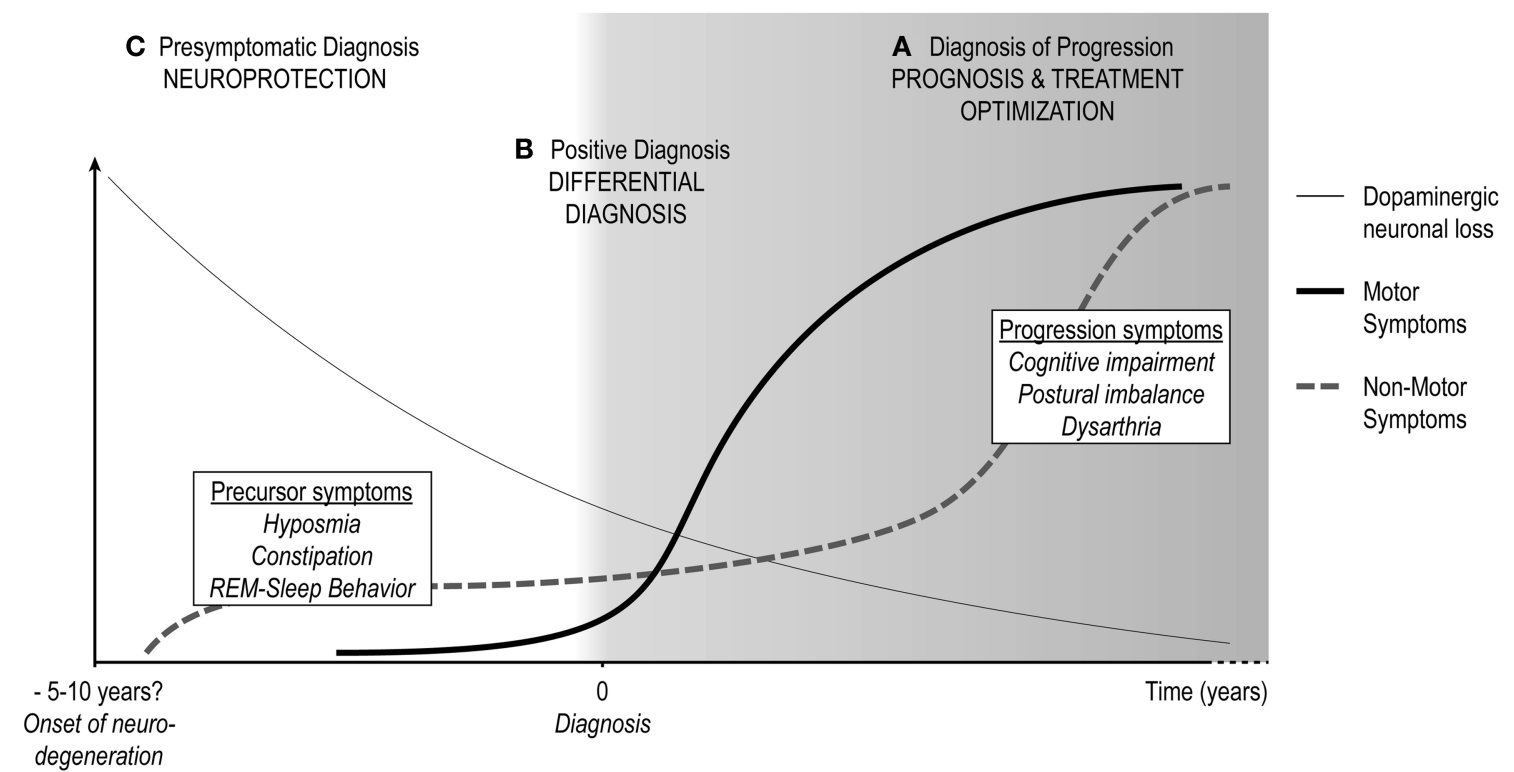

Premotor phase

Symptomatic PD

FIGURE 1 |The three purposes of biomarkers in Parkinson's disease. Schematic representation of the clinical progression of Parkinson's disease (PD). The thin line represents the continuous degeneration of the dopaminergic neurons of the substantia nigra. When dopaminergic neuronal loss reaches $>50 \%$, cardinal motor symptoms appear (thick line) and PD becomes fully symptomatic (gray background). Motor symptoms worsen over time but respond to dopamine replenishment therapy. During the premotor phase (white background) non-motor symptoms (dotted line) may already be present. Non-motor symptoms burden also increases with time but contrary to motor symptoms do not respond to treatment and constitute most of the disability in advanced PD. Biomarkers for PD can serve three main purposes: (A) Diagnosis of progression to end-stage non-motor impairment, which would help predict bad prognosis and can serve to monitor neuroprotective therapies. (B) Positive diagnosis of PD by differentiating it from other causes of parkinsonism. (C) Presymptomatic diagnosis of PD. Although non-specific, precursor non-motor symptoms such as constipation, depression, hyposmia, or REM-sleep behavior disorders characterize a population in which future biomarkers for presymptomatic diagnosis should be tested.
(Martin et al., 2008) and dosage of neuronal protein involved in the pathogenesis of the disease in the cerebrospinal fluid (Hong et al., 2010) are new tools that are likely to help in the diagnosis and management of PD patients in the near future. Nevertheless, as stated in a recent review, no fully validated biomarker for PD is available yet (Marek et al., 2008) and there is still a need for new biomarkers that will complement the ones already available.

\section{PD PATHOLOGY EXTENDS WELL BEYOND \\ THE SUBSTANTIA NIGRA}

The traditional assumption of PD as a primary disorder of the dopaminergic neurons of the $\mathrm{SN}$ has been reconsidered in recent years. The SN is neither the earliest nor the most severely affected region since more caudal brainstem structures as well as the olfactory bulb are involved earlier and more severely in most cases (Del Tredici et al., 2002; Braak et al., 2003). Nuclei such as the dorsal motor nucleus of the vagus nerve display early and massive degenerative changes that worsen as the disease progresses, until a total neuronal loss is reached (Braak et al., 2002). The density of LB and $\mathrm{LN}$ in brainstem nuclei is thought to follow an inverted $\mathrm{U}$-shaped curve, with a progressive disappearance in end-stages where no vulnerable neurons are left.

Furthermore, recent studies have demonstrated that the presence of Lewy pathology is much more extensive and affects not only the central nervous system (CNS) but also peripheral autonomic neuronal circuits (Wakabayashi et al., 1988, 1993; Wakabayashi and Takahashi, 1997; Braak et al., 2006, 2007; Braak and Del Tredici, 2008). Interestingly, the same temporal pattern of degeneration has been demonstrated in peripheral structures such as sympathetic ganglia (Orimo et al., 2008).

Lewy pathology has been reported to be present in the olfactory bulbs of subjects with PD as well as a subset of asymptomatic subjects. The presence of Lewy inclusions in neurologically unimpaired patients is called incidental Lewy body disease (ILBD; DelleDonne et al., 2008), since it is thought to represent premotor PD (Del Tredici et al., 2002; Braak et al., 2003; Beach et al., 2010). A recent comprehensive survey has shown that LB were readily retrieved in the olfactory bulbs of 55 out of 58 autopsied patients with PD (Beach et al., 2010). The involvement of the olfactory bulb in most ILBD patients suggests that it occurs at the earliest stage of disease (Bloch et al., 2006; Beach et al., 2009).

The autonomic nervous system (ANS), composed of parasympathetic and sympathetic division, is distributed to the peripheral tissues and organs by way of autonomic ganglia. Control centers of the diencephalon and brainstem send fibers to synapse on preganglionic neurons located in the brainstem or in the spinal cord. From these neurons, preganglionic fibers project out of the CNS to synapse on neurons in the autonomic ganglia. Postganglionic fibers emerge and form terminal networks on the target tissue. The enteric nervous system (ENS) could be considered part of 
the ANS and be regarded as a complex postganglionic neuronal network. The ENS contains as many neurons as the spinal cord (approximately 80-100 million neurons) and the functional and chemical diversity of enteric neurons closely resembles that of the CNS (Benarroch, 2007; Cersosimo and Benarroch, 2008). This integrated neuronal network is organized in two ganglionated plexuses, myenteric and submucosal, composed of neurons and enteric glial cells (Benarroch, 2007; Lebouvier et al., 2009a). Neurons of the myenteric plexus (or Auerbach's) control the activity of the smooth muscle of the gut whereas those in the submucosal plexus (or Meissner's) regulate mucosal secretion and blood flow (Schemann and Neunlist, 2004).

Lewy pathology has been described in the autonomic nuclei of the brainstem and spinal cord and in the sympathetic ganglia of PD patients (Wakabayashi et al., 1988, 1993; Wakabayashi and Takahashi, 1997; Braak et al., 2006, 2007; Braak and Del Tredici, 2008) and ILBD subjects (Bloch et al., 2006; Minguez-Castellanos et al., 2007). Remarkably, LB and LN are also present in postganglionic structures. Using sampled skin from the chest and forearm of autopsied patients, Ikemura et al. (2008) demonstrated LN in the sympathetic nerve fascicles of the dermis and subcutaneous tissue in 10 out of $14 \mathrm{PD}$ patients and in one of two ILBD. The autonomic innervation of the submandibular gland also displays LN with a high sensitivity in two autopsy surveys, with lesions in 14 out of 15 PD patients (Beach et al., 2010) and 9 of 9 PD patients respectively (Del Tredici et al., 2010). Moreover, LN were present in the submandibular glands of two out of three ILBD subjects (Del Tredici et al., 2010). Regarding the ENS, the presence of Lewy pathology in the gastrointestinal tract was described more than 20 years ago in two seminal reports (Qualman et al., 1984; Kupsky et al., 1987). Wakabayashi et al. (1988) found LB in the gastrointestinal tract of seven consecutive autopsies performed in PD patients and more recently Beach et al. (2010) reported LB and LN in the gut of 11 of 17 PD patients. In both studies, the Lewy pathology was distributed in the MP and SMP from the upper esophagus to the rectum following a rostrocaudal gradient, the upper esophagus being more severely affected than the colon and the rectum (Wakabayashi et al., 1988; Beach et al., 2010). Remarkably, when specific histochemical procedures were used (analysis of multiple slides of thick sections of the lower esophagus), Lewy inclusions were found in 14 out of $15 \mathrm{PD}$ patients, suggesting that the pathology is scattered but nearly constant in the ENS (Beach et al., 2010). Among ILBD patients, the rate of enteric pathology varies depending on the sampling and techniques used to assess the synucleinopathy, from $1 / 7$ to $14 / 17$ (Bloch et al., 2006). A thorough assessment of the ENS in ILBD is still needed to test the hypothesis of its prime involvement during PD (Braak et al., 2006).

The histopathological features observed in the olfactory bulb and in the peripheral nervous system of PD patients are likely to be specific for this neurodegenerative condition. Indeed, although the olfactory bulb is constantly affected by the pathological process in multiple system atrophy, the inclusions of alpha-synuclein are mainly glial (Kovacs et al., 2003). The Lewy pathology in the peripheral nervous system of multiple system atrophy patients is primarily preganglionic and, in contrast to $\mathrm{PD}$, the postganglionic network is almost completely spared (Ikemura et al., 2008; Orimo et al., 2008; Del Tredici et al., 2010). Regarding PSP, tau pathology is minimal or absent in the olfactory bulb and no specific involvement of the peripheral nervous system has been reported yet (Rub et al., 2002).

Altogether, these results demonstrate that PD pathology extends well beyond the substantia nigra and that the peripheral autonomic neuronal circuits are affected early, and specifically in a large proportion of patients.

\section{BIOPSABLE NEURAL TISSUES AS A NEW SOURCE OF BIOMARKER OF PD}

Remarkably, some of the extranigral structures affected by Lewy pathology are accessible to biopsies, making them a putative original source of biomarkers. As the only component of the olfactory system accessible to biopsy, olfactory epithelium was logically screened for Lewy pathology. In a pilot study, there was no evidence of disease-specific pathology in seven hypo/anosmic PD patients (Witt et al., 2009). This is probably explained by the fact that the pathology in the olfactory system is restricted to the olfactory bulb, a structure that is not accessible to routine biopsies (Parkkinen et al., 2009).

Quite logically, from the results obtained in autopsy specimens, a Japanese team attempted to retrieve Lewy pathology using routine skin biopsies from chest and leg. The results were disappointing as only two patients were positive in a series of 20 parkinsonian patients (Miki et al., 2010). The discrepancy between the results of the autopsy-based study and the in vivo study may be explained by the differences of the sites for tissue samples, the size of skin tissue examined, and the numbers of examined sections. In any event, this does not make the skin a source of biomarker for the premortem diagnosis of PD.

The two autopsy studies of the submandibular gland in LB disorders raised a recent interest for the salivary glands (Beach et al., 2010; Del Tredici et al., 2010). Apart from fine needle aspiration biopsies that only give access to smears of epithelial cells, histological analysis of the submandibular gland can only be achieved though incisional biopsy. The possibility of injury to the marginal mandibular branch of the facial, hypoglossal, and lingual nerves requires the biopsy to be performed in the operating room. Because of the risks and technical difficulties of such a procedure, even higher when it comes to the parotid gland, the analysis of the major salivary glands will probably never become a routine biomarker for PD. Conversely, minor salivary gland biopsy is safe and routinely performed for diagnostic purposes (Caporali et al., 2008). Provided that minor salivary glands recapitulate the alterations of the autonomic innervation observed in the submandibular gland, which requires confirmation, the analysis of labial salivary glands may provide a useful histological biomarker (Cersosimo et al., 2010).

The ENS displays specific features that make it a prime candidate for being a histopathological marker of PD. In contrast to all aforementioned tissues, it does not contain only postganglionic neuronal processes but rather is an integrated neuronal network that contains neurons and enteric glial cells, the counterpart of the astrocytes of the CNS. It is sometimes referred as a "second brain" because of the functional and chemical diversity of the enteric neurons that closely resembles that of the CNS. We have shown recently that whole-mounts of submucosa from routine colonic biopsies allow a morphological and quantitative analysis of the SMP (Lebouvier 


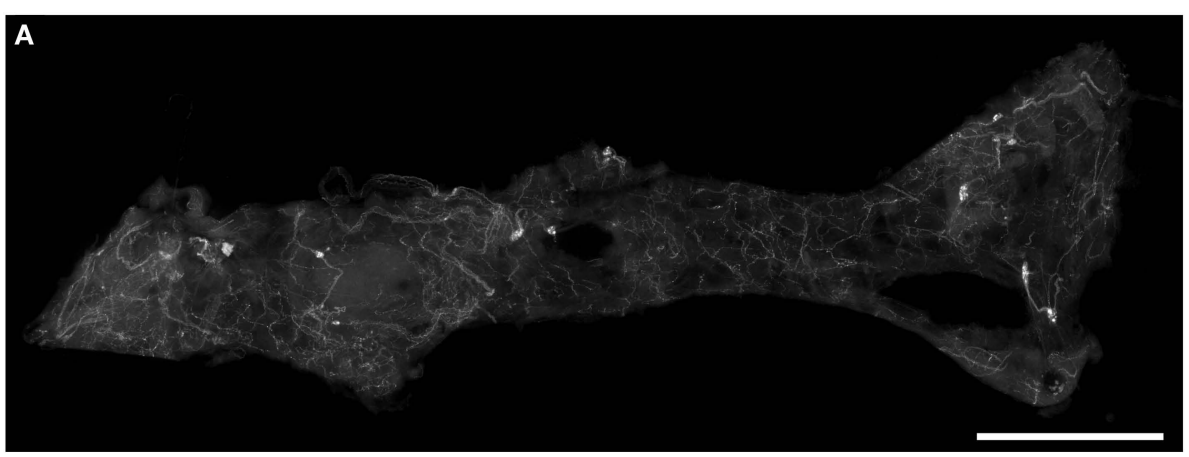

B
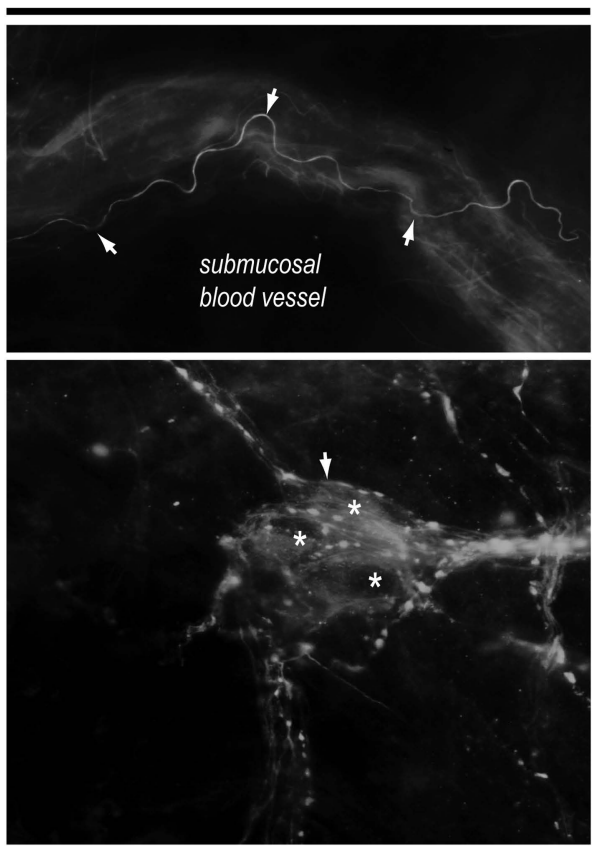

FIGURE 2 | Routine colonoscopy biopsies as a novel biomarker of Parkinson's disease. (A) Whole mount of submucosa microdissected from a standard colonoscopy biopsy and immunostained with anti-neurofilament antibody to unravel the neural network. Colonic submucosal (Meissner's) plexus, formed by ganglia and interganglionic strands, is readily apparent. A single biopsy performed in the ascending or descending colon gives access to a mean of 150

et al., 2009b). A single standard colonic biopsy contains an average of 35 ganglia, thus allowing the analysis of approximately 150 neurons (Figure 2A). Using this approach, $\mathrm{LN}$ were identified in the SMP of four out of five PD patients (Lebouvier et al., 2008) in a preliminary report (Figure $2 \mathrm{~B}$ ). We have therefore undertaken a large-scale survey to correlate the amount of enteric pathology with clinical PD symptoms. A total of 10 control and 30 PD patients were enrolled. Four routine colonic biopsies were taken from the ascending and descending colon during the course of a total colonoscopy. Lewy pathology was apparent in the colonic biopsies from 21 patients (72\%) and in none of the controls. In favor of the pathogenicity of enteric pathology, pathological burden was correlated with an apparent neuronal loss within the submucosal plexus. The clinical relevance of these findings was supported by a correlation between pathological burden and constipation as well as the amount of axial and dopa-unresponsive symptoms, which reflect disease progression (Lebouvier et al., 2010).

\section{CONCLUSION AND PERSPECTIVES}

Although Lewy pathology is absent in a minority of cases of clinical $\mathrm{PD}$, most of which are rare genetic forms of the disease, alpha-synuclein is still considered to be a key player of the pathophysiology of $\mathrm{PD}$. In the era of functional neuroimaging and molecular biology, histological biomarkers may still be of great interest for the diagnosis and management of PD because they are the only to directly assess the synucleinopathy in vivo. By affecting the peripheral ANS 
early in the course of the disease, PD provides a nearly unique opportunity to directly apprehend the neuropathological process in biopsable neural tissues. Apart from PD, comparable approaches have been used only in variant Creutzfeldt-Jakob Disease. Though analysis is performed in non-neural lymphoid tissue, histochemical (Ironside et al., 2000) and biochemical (Wadsworth et al., 2001) methods can identify the pathological form of the prion protein in tonsil biopsies from affected individuals.

To date, the search for sensitive histological biomarkers in PD has been hindered by the scattered pattern of inclusions in the peripheral ANS. Among routinely accessible tissues, the extraordinary neuronal density of the ENS accounts for the higher, yet imperfect, sensitivity of gut biopsies to detect the pathology. The good correlation between pathology burden and disease severity makes the technique a readily available biomarker to assess disease progression (Figure 1A).

Yet future work is needed to test the specificity of these peripheral inclusions in larger series and to improve the sensitivity of the technique. Possible strategies include an increased number of colonic samples or the use of upper digestive tract biopsies, which add the potential risk of inhalation during the endoscopy. Other biopsable tissues such as minor salivary glands may solve the safety issues if they demonstrate an equal or superior sensitivity to evidence Lewy inclusions. Once the sensitivity is improved, the primary goal will be to use such biomarkers for the positive diagnosis of PD and differential diagnosis with other forms of parkinsonism (Figure 1B).

A new conception of the neuropathology of PD supports a centripetal pattern of degeneration from postganglionic and peripheral autonomic neurons to their central and preganglionic counter-

\section{REFERENCES}

Abbott, R. D., Petrovitch, H., White, L. R., Masaki, K. H., Tanner, C. M., Curb, J. D., Grandinetti, A., Blanchette, P. L., Popper, J. S., and Ross, G. W. (2001). Frequency of bowel movements and the future risk of Parkinson's disease. Neurology 57, 456-462.

Ahlskog, J.E. (2007). Beating a dead horse: dopamine and Parkinson disease. Neurology 69, 1701-1711.

Anderson, J. P., Walker, D. E., Goldstein, J. M., de Laat, R., Banducci, K., Caccavello, R. J., Barbour, R., Huang, J., Kling, K., Lee, M., Diep, L., Keim, P. S., Shen, X., Chataway, T., Schlossmacher, M. G., Seubert, P., Schenk, D., Sinha, S., Gai, W. P., and Chilcote, T. J. (2006). Phosphorylation of Ser-129 is the dominant pathological modification of alpha-synuclein in familial and sporadic Lewy body disease. J. Biol. Chem. 281, 29739-29752.

Beach, T. G., Adler, C. H., Sue, L. I., Vedders, L., Lue, L., White Iii, C. L., Akiyama, H., Caviness, J. N., Shill, H. A., Sabbagh, M. N., and Walker, D. G. (2010). Multi-organ distribution of phosphorylated alpha-synuclein histopathology in subjects with Lewy body disorders. Acta Neuropathol. 119, 689-702.
Beach, T. G., White, C. L., III, Hladik, C. L., Sabbagh, M. N., Connor, D. J., Shill, H. A., Sue, L. I., Sasse, J., Bachalakuri, J., Henry-Watson, J., Akiyama, H., and Adler, C. H. (2009). Olfactory bulb alpha-synucleinopathy has high specificity and sensitivity for Lewy body disorders. Acta Neuropathol. 117, 169-174.

Benarroch, E. E. (2007). Enteric nervous system: functional organization and neurologic implications. Neurology69, 1953-1957.

Berg, D., and Becker, G. (2002). Perspectives of B-mode transcranial ultrasound. Neuroimage 15, 463-473.

Bloch, A., Probst, A., Bissig, H., Adams, H., and Tolnay, M. (2006). Alphasynuclein pathology of the spinal and peripheral autonomic nervous system in neurologically unimpaired elderly subjects. Neuropathol. Appl. Neurobiol. 32, 284-295.

Braak, H., and Del Tredici, K. (2008). Invited article: nervous system pathology in sporadic Parkinson disease. Neurology 70, 1916-1925.

Braak, H., Del Tredici, K., Bratzke, H., Hamm-Clement, J., Sandmann-Keil, D., and Rub, U. (2002). Staging of the intracerebral inclusion body pathology associated with idiopathic Parkinson's

part, and then a cranial spreading within the brainstem until the substantia nigra is finally reached (Orimo et al., 2008; Hawkes et al., 2009). Suitable histological biomarkers utilize the postganglionic neurons, which are supposed to herald the degenerative process. Hence beyond positive diagnosis, the next step is to use them for the premotor diagnosis of PD (Figure 1C). Routinely accessible biomarkers would allow the screening of vulnerable populations for Lewy inclusions before the advent of the motor symptoms. Delineation of the spectrum of Parkinson's at risk patients is currently under work (Stern and Siderowf, 2010), but surely includes patients with REM-sleep behavior disorder. Patients above 50 years presenting with abnormalities in olfaction or gastrointestinal function, particularly if justifying an endoscopy, could as well be systematically assessed.

Until imaging probes for in vivo detection of alpha-synuclein deposition become available (Kikuchi et al., 2010), we believe there is a time-window for histological biomarkers in LB diseases. Accumulating data suggest that they should contribute to the early diagnosis of $\mathrm{PD}$, and thus facilitate earlier diagnosis to evaluate neuroprotective treatments.

\section{ACKNOWLEDGMENTS}

Work in our lab is supported by the Michael J Fox Foundation, France Parkinson, CECAP (Comité d'Entente et de Coordination des Associations de Parkinsoniens), ADPLA (Association des Parkinsoniens de Loire Atlantique), FFPG (Fédération française des groupements parkinsoniens) and Parkinsoniens de Vendée. TL is a recipient of poste d'accueil Inserm. MN and PDe are both recipients of contrats d'Interface Inserm.

disease (preclinical and clinical stages). J. Neurol. 249(Suppl. 3), III/1-III/5.

Braak, H., Del Tredici, K., Rub, U., de Vos, R. A., Jansen Steur, E. N., and Braak, E. (2003). Staging of brain pathology related to sporadic Parkinson's disease. Neurobiol. Aging 24, 197-211.

Braak, H., de Vos, R. A., Bohl, J., and Del Tredici, K. (2006). Gastric alpha-synuclein immunoreactive inclusions in Meissner's and Auerbach's plexuses in cases staged for Parkinson's diseaserelated brain pathology. Neurosci. Lett. 396, 67-72.

Braak, H., Sastre, M., Bohl, J. R., de Vos, R. A., and Del Tredici, K. (2007). Parkinson's disease: lesions in dorsal horn layer I, involvement of parasympathetic and sympathetic preand postganglionic neurons. Acta Neuropathol. 113, 421-429.

Caporali, R., Bonacci, E., Epis, O., Bobbio-Pallavicini, F., Morbini, P., and Montecucco, C. (2008). Safety and usefulness of minor salivary gland biopsy: retrospective analysis of 502 procedures performed at a single center. Arthritis Rheum. 59, 714-720.

Cersosimo, M. G., and Benarroch, E. E. (2008). Neural control of the gastrointestinal tract: implications for
Parkinson disease. Mov. Disord. 23, 1065-1075.

Cersosimo, M.G., Perandones, C., Micheli, F. E., Raina, G. B., Beron, A. M. Nasswetter, G. M. R., and Benarroch, E. E. (2010). "Alpha-synuclein immunoreactivity in minor salivary glands: a potential pathological biomarker for Parkinson's disease?," in 14th International Congress on Parkinson's Disease and Movement Disorders, Buenos Aires, Argentina.

Chaudhuri, K. R., Healy, D. G., and Schapira, A. H. (2006). Non-motor symptoms of Parkinson's disease: diagnosis and management. Lancet Neurol. 5, 235-245.

DelleDonne, A., Klos, K. J., Fujishiro, H., Ahmed, Z., Parisi, J. E., Josephs, K. A., Frigerio, R., Burnett, M., Wszolek, Z. K., Uitti, R. J., Ahlskog, J. E., and Dickson, D. W. (2008). Incidental Lewy body disease and preclinical Parkinson disease. Arch. Neurol. 65, 1074-1080.

Del Tredici, K., Hawkes, C. H., Ghebremedhin, E., and Braak, H. (2010). Lewy pathology in the submandibular gland of individuals with incidental Lewy body disease and sporadic Parkinson's disease. Acta Neuropathol. 119, 703-713. 
Del Tredici, K., Rub, U., De Vos, R. A., Bohl, J.R., and Braak, H. (2002). Where does Parkinson disease pathology begin in the brain? J Neuropathol. Exp. Neurol. $61,413-426$.

Fujiwara, H., Hasegawa, M., Dohmae, N., Kawashima, A., Masliah, E., Goldberg, M. S., Shen, J., Takio, K., and Iwatsubo, T. (2002). alpha-Synuclein is phosphorylated in synucleinopathy lesions. Nat. Cell Biol. 4, 160-164.

Hawkes, C. H., Del Tredici, K., and Braak, H. (2009). Parkinson's disease: the dual hit theory revisited. Ann. N. Y. Acad. Sci. 1170, 615-622.

Hong, Z., Shi, M., Chung, K. A., Quinn, J. F., Peskind, E. R., Galasko, D., Jankovic, J., Zabetian, C. P., Leverenz, J. B., Baird, G., Montine, T. J., Hancock, A. M., Hwang, H., Pan, C., Bradner, J., Kang, U. J., Jensen, P. H., and Zhang, J. (2010). DJ-1 and alpha-synuclein in human cerebrospinal fluid as biomarkers of Parkinson's disease. Brain 133, 713-726.

Hughes, A. J., Daniel, S. E., Ben-Shlomo, Y., and Lees, A. J. (2002). The accuracy of diagnosis of parkinsonian syndromes in a specialist movement disorder service. Brain 125, 861-870.

Ikemura, M., Saito, Y., Sengoku, R., Sakiyama, Y., Hatsuta, H., Kanemaru, K., Sawabe, M., Arai, T., Ito, G., Iwatsubo, T., Fukayama, M., and Murayama, S. (2008). Lewy body pathology involves cutaneous nerves. J. Neuropathol. Exp. Neurol. 67, 945-953.

Ironside, J. W., Hilton, D. A., Ghani, A., Johnston, N. J., Conyers, L., McCardle, L. M., and Best, D. (2000). Retrospective study of prion-protein accumulation in tonsil and appendix tissues. Lancet 355, 1693-1694.

Kikuchi, A., Takeda, A., Okamura, N., Tashiro, M., Hasegawa, T., Furumoto, S., Kobayashi, M., Sugeno, N., Baba, T., Miki, Y., Mori, F., Wakabayashi, K., Funaki, Y., Iwata, R., Takahashi, S., Fukuda, H., Arai, H., Kudo, Y., Yanai, $\mathrm{K}$., and Itoyama, Y. (2010). In vivo visualization of alpha-synuclein deposition by carbon-11-labelled 2-[2-(2-dimethylaminothiazol-5-yl)ethenyl]-6-[2(fluoro)ethoxy]benzoxazole positron emission tomography in multiple system atrophy. Brain 133, 1772-1778.

Kovacs, T., Papp, M. I., Cairns, N. J., Khan, M. N., and Lantos, P. L. (2003). Olfactory bulb in multiple system atrophy. Mov. Disord. 18, 938-942.

Kupsky, W. J., Grimes, M. M., Sweeting, J., Bertsch, R., and Cote, L. J. (1987). Parkinson's disease and megacolon: concentric hyaline inclusions (Lewy bodies) in enteric ganglion cells. Neurology 37, 1253-1255.

Lebouvier, T., Chaumette, T., Damier, P., Coron, E., Touchefeu, Y., Vrignaud, S., Naveilhan, P., Galmiche, J. P., Bruley des Varannes, S., Derkinderen, P., and Neunlist, M. (2008). Pathological lesions in colonic biopsies during Parkinson's disease. Gut 57, 1741-1743.

Lebouvier, T., Chaumette, T., Paillusson, S., Duyckaerts, C., Bruley des Varannes, S., Neunlist, M., and Derkinderen, P. (2009a). The second brain and Parkinson's disease. Eur. J. Neurosci. 30, 735-741.

Lebouvier, T., Coron, E., Chaumette, T., Paillusson, S., Bruley des Varannes, S., Neunlist, M., and Derkinderen, P. (2009b). Routine colonic biopsies as a new tool to study the enteric nervous system in living patients. Neurogastroenterol Motil. 22, e11-e14.

Lebouvier, T., Neunlist, M., Bruley Des Varannes, S., Coron, E., Drouard, A., Nguyen, J. P., Chaumette, T., Tasselli, M., Paillusson, S., Flamand, M., Galmiche, J. P., Damier, P., and Derkinderen, P. (2010). Colonic biopsies to assess the neuropathology of Parkinson's disease and its relationship with symptoms. PLoS ONE (in press).

Lees, A. J., Hardy, J., and Revesz, T. (2009). Parkinson's disease. Lancet 373, 2055-2066.

Marek, K., Jennings, D., Tamagnan, G., and Seibyl, J. (2008). Biomarkers for Parkinson's [corrected] disease: tools to assess Parkinson's disease onset and progression. Ann. Neurol.64(Suppl. 2), S111-S121.

Martin, W. R., Wieler, M., and Gee, M. (2008). Midbrain iron content in early Parkinson disease: a potential biomarker of disease status. Neurology 70, 1411-1417.

Miki, Y., Tomiyama, M., Ueno, T., Haga, R., Nishijima, H., Suzuki, C., Mori, F., Kaimori, M., Baba, M., and Wakabayashi, K. (2010). Clinical availability of skin biopsy in the diagnosis of Parkinson's disease. Neurosci. Lett. $469,357-359$.

Minguez-Castellanos, A., Chamorro, C. E., Escamilla-Sevilla, F., OrtegaMoreno, A., Rebollo, A. C., GomezRio, M., Concha, A., and Munoz, D. G. (2007). Do alpha-synuclein aggregates in autonomic plexuses predate Lewy body disorders?: a cohort study. Neurology 68, 2012-2018.

Olanow, C. W., Rascol, O., Hauser, R., Feigin, P. D., Jankovic, J., Lang, A., Langston, W., Melamed, E., Poewe,
W., Stocchi, F., and Tolosa, E. (2009). A double-blind, delayed-start trial of rasagiline in Parkinson's disease. $N$. Engl. J. Med. 361, 1268-1278.

Orimo, S., Uchihara, T., Nakamura, A., Mori, F., Kakita, A., Wakabayashi, K., and Takahashi, H. (2008). Axonal alpha-synuclein aggregates herald centripetal degeneration of cardiac sympathetic nerve in Parkinson's disease. Brain 131, 642-650.

Parkkinen, L., Silveira-Moriyama, L., Holton, J. L., Lees, A. J., and Revesz, T. (2009). Can olfactory bulb biopsy be justified for the diagnosis of Parkinson's disease? Comments on "olfactory bulb alpha-synucleinopathy has high specificity and sensitivity for Lewy body disorders". Acta Neuropathol. 117, 213-214; author reply $217-218$.

Ponsen, M. M., Stoffers, D., Booij, J., van Eck-Smit, B. L., Wolters, E., and Berendse, H. W. (2004). Idiopathic hyposmia as a preclinical sign of Parkinson's disease. Ann. Neurol. 56, 173-181.

Postuma, R. B., Gagnon, J. F., Vendette, M., Fantini, M. L., Massicotte-Marquez, J., and Montplaisir, J. (2009). Quantifying the risk of neurodegenerative disease in idiopathic REM sleep behavior disorder. Neurology 72, 1296-1300.

Qualman, S.J., Haupt, H. M., Yang, P., and Hamilton, S. R. (1984). Esophageal Lewy bodies associated with ganglion cell loss in achalasia. Similarity to Parkinson's disease. Gastroenterology 87, 848-856.

Rub, U., Del Tredici, K., Schultz, C., de Vos, R. A., Jansen Steur, E. N., Arai, K., and Braak, H. (2002). Progressive supranuclear palsy: neuronal and glial cytoskeletal pathology in the higher order processing autonomic nuclei of the lower brainstem. Neuropathol. Appl. Neurobiol. 28, 12-22.

Savica, R., Carlin, J. M., Grossardt, B. R., Bower, J. H., Ahlskog, J. E., Maraganore, D. M., Bharucha, A. E., and Rocca, W. A. (2009). Medical records documentation of constipation preceding Parkinson disease: a case-control study. Neurology 73 , 1752-1758.

Schapira, A. H., and Olanow, C.W. (2004). Neuroprotection in Parkinson disease: mysteries, myths, and misconceptions. JAMA 291, 358-364.

Schemann, M., and Neunlist, M. (2004). The human enteric nervous system. Neurogastroenterol. Motil. 16(Suppl. 1), 55-59.

Stern, M. B., and Siderowf, A. (2010). Parkinson's at risk syndrome: can
Parkinson's disease be predicted? Mov . Disord. 25(Suppl. 1), S89-S93.

Thobois, S., Delamarre-Damier, F., and Derkinderen, P. (2005). Treatment of motor dysfunction in Parkinson's disease: an overview. Clin. Neurol. Neurosurg. 107, 269-281.

Wadsworth, J. D., Joiner, S., Hill, A. F., Campbell, T. A., Desbruslais, M., Luthert, P. J., and Collinge, J. (2001). Tissue distribution of protease resistant prion protein in variant Creutzfeldt-Jakob disease using a highly sensitive immunoblotting assay. Lancet 358, 171-180.

Wakabayashi, K., and Takahashi, H. (1997). Neuropathology of autonomic nervous system in Parkinson's disease. Eur. Neurol. 38(Suppl. 2), 2-7.

Wakabayashi, K., Takahashi, H., Ohama, E., Takeda, S., and Ikuta, F. (1993). Lewy bodies in the visceral autonomic nervous system in Parkinson's disease. Adv. Neurol. 60, 609-612.

Wakabayashi, K., Takahashi, H., Takeda, S., Ohama, E., and Ikuta, F. (1988) Parkinson's disease: the presence of Lewy bodies in Auerbach's and Meissner's plexuses. Acta Neuropathol. 76, 217-221.

Witt, M., Bormann, K., Gudziol, V., Pehlke, K., Barth, K., Minovi, A., Hahner, A. Reichmann, H., and Hummel, T. (2009). Biopsies of olfactory epithelium in patients with Parkinson's disease. Mov. Disord. 24, 906-914.

Conflict of Interest Statement: The authors declare that the research was conducted in the absence of any commercial or financial relationships that could be construed as a potential conflict of interest.

Received: 25 June 2010; paperpending published: 16 July 2010; accepted: 11 August 2010; published online: 03 September 2010.

Citation: Lebouvier T, Tasselli M, Paillusson $S$, Pouclet $H$, Neunlist $M$ and Derkinderen P (2010) Biopsable neural tissues: toward new biomarkers for Parkinson's disease? Front. Psychiatry 1:128. doi: 10.3389/ fpsyt.2010.00128

This article was submitted to Frontiers in Neurodegeneration, a specialty of Frontiers in Psychiatry.

Copyright (ㅇ 2010 Lebouvier, Tasselli, Paillusson, Pouclet, Neunlist and Derkinderen. This is an open-access article subject to an exclusive license agreement between the authors and the Frontiers Research Foundation, which permits unrestricted use, distribution, and reproduction in any medium, provided the original authors and source are credited. 